\title{
The Impact of Ethical Leadership on Work-to-Family Enrichment
}

\author{
Lin QIU \\ School of Business Administration, South China University of Technology, Guangzhou, China \\ linqiu@scut.edu.cn
}

Keywords: Leader-member exchange, Work-to-family enrichment, Work engagement.

\begin{abstract}
The present study investigates the impact of ethical leadership as perceived by followers on their work-to-family enrichment (WFE) by focusing on the mediating role of job autonomy and work engagement. The results from a survey of 186 working adults in China provide support for the hypotheses, indicating that perceived ethical leadership is positively related to WFE; this relationship is also partially mediated by job autonomy and work engagement. The theoretical and managerial implications of these findings are discussed.
\end{abstract}

\section{Introduction}

Given that leaders play a critical role in setting the ethical tone for the organization [1], researchers are increasingly turning their attention to the ethical behavior of leaders and how such behavior affects employees. Ethical leadership refers to the display of behaviors consistent with appropriate norms, which is visible through leader actions and relationships [2]. The perception of ethical leaders has been linked to employee commitment, increased positive employee attitudes and behaviors, and ultimately, improved organizational performance [3].

Despite this progress, not much has been known about the effect of ethical leadership on more direct ethical outcomes, such as employee work-family interface. Work and family represent the two most important roles for working adults, and the interactions between the two life roles have implications for both individuals and organizations [4]. A better understanding of the effect of ethical leadership on employee work-family interface is, therefore, both theoretically important to enriching insights on the leader influence process, and practically relevant for managing work-family relationship through ethical leadership.

Therefore, this study aims to link ethical leadership to work-family enrichment, the processes in which experiences in work or family role improve the quality of life in the other role [5]. In addition, although there is a wealth of literature on the proximal effects of ethical leadership, little is known about the process through which ethical leadership influences employee outcomes. To echo a recent call to explore the underlying mechanisms and processes by which ethical leadership exerts its influence on the employee outcomes [6], the present study also aims to examine the indirect effects of LMX on work-family enrichment through job autonomy and work engagement. These ideas are graphically summarized in Figure 1.

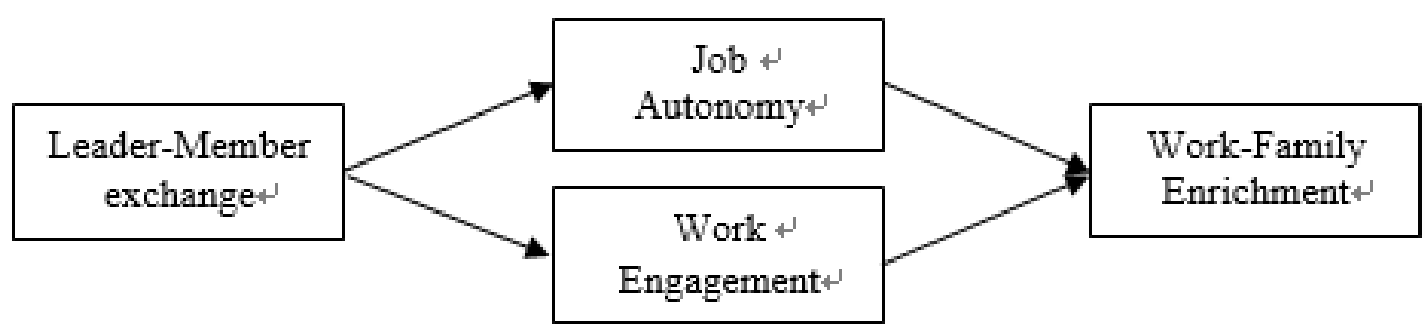

Figure 1. Conceptual model 


\section{Literature Review and Hypotheses}

\section{Work-Family Enrichment.}

Due to changes in demographics (more dual-earner or dual-career couples and single-parent families) and working conditions (more job insecurity and more blurring of boundaries between work and family), managing work-family relationship has become a critical and highly salient challenge for employees and employers [7]. However, combining work and family roles also provides benefits and opportunities for enrichment. The experience of work-family enrichment is traditionally described using role expansion theory, which suggests participation in multiple roles can produce positive outcomes for individuals [5].

It is recognized that work can benefit family as well as that family can benefit work [5]. Work-to-family enrichment (WFE) occurs when work experiences improve the quality of family life, and family-to-work enrichment (FWE) occurs when family experiences improve the quality of work life. The present research focuses on WFE because it has been believed that resources in work domain influence WFE rather than FWE [4], and ethical leadership primarily exists in the work domain. A number of studies have demonstrated that WFE facilitates various positive outcomes (e.g., organizational commitment; job, family, and life satisfaction; physical and mental health) [4]. Therefore, understanding processes by which employees enrich their family-life quality is very important.

\section{Ethical Leadership and WFE.}

It has been believed that the essence of effective leadership is ethical behavior [8]. Ethical leadership is defined as "the demonstration of normatively appropriate conduct through personal actions and interpersonal relationships, and the promotion of such conduct to followers through two-way communication, reinforcement, and decision-making" [2]. When leaders set high ethical standards for themselves as well as others, employees are likely to emulate and internalize the value driven behaviors of their role modeling ethical leaders [8]. In addition, work-family enrichment theory posits that the skills and perspectives acquired in the workplace are capable of being transferred to the family domain, thereby helping employees to enrich their family life [5]. That is, when leaders behave ethically, communicate the importance of ethics, and treat their followers fairly, employees tend to engage in ethically behaviors at home and consequently, improve the quality of their family life [6]. Hence, this study suggests that employees who learn from ethical leaders in the workplace are inclined to display ethical leadership in the family domain, which can help them to improve the quality of their family lives.

H1: Ethical leadership is positively related to WFE.

\section{The Mediating Role of Job Autonomy.}

According to work-family enrichment theory, generation of resources is a crucial driver of the enrichment process [5]. Greenhaus and Powell (2006) identified five types of resources are critical in facilitating the process of WFE, including skills and perspectives, psychological and physical resources, social capital resources, flexibility, and material resources [5]. As a kind of flexibility resources, job autonomy refers to the degree to which the job provides substantial freedom, independence, and discretion to the employee in scheduling the work and in determining the procedure to be used in carrying it out. Job autonomy may promote family functioning because it affords more time for family, as well increased energy, skills, and attitudes [5]. The positive link between job autonomy and WFE has been established in previous studies [9].

Leadership has been considered as an important source from which employees can obtain transferrable resources that enrich their family lives [10] Ethical leaders are described as fair and genuinely concerned for their employees [8]. They tend to offer employees high levels of autonomy and influence over decision making [2]. Empirical research has confirmed the strong link between ethical leadership and job autonomy [11]. Work-family enrichment theory sheds light on resource 
generation in one domain and consequences in another domain by focusing on the mediating role of transferable resources [5] Therefore, ethical leaders tend to offer employees high levels of job autonomy, and this may allow employees to manage their job demands and fulfill their family responsibilities, which in turn enhances the quality of their family life.

H2: Job autonomy will mediate the positive relation between ethical leadership and WFE.

\section{Work Engagement as a Mediator.}

Work engagement is defined as a positive, fulfilling, work-related state of mind [8]. Engaged employees can contribute to organizational success through their drive and energy to be productive, exhibiting enhanced in-role job performance and extra-role behaviors, and less likely to leave the organization [9]. Ethical leaders enjoy a high-quality, exchange-oriented relationship with their followers and engage in behaviors that are beneficial for their followers [8]. When employees are treated fairly and well by the leader, they are likely to think about their relationship with the leader and organization in terms of social exchange rather than economic exchange [12]. According to social exchange theory, when individuals feel that a person (such as an ethical leader) or organization has treated them positively, they feel obliged to reciprocate such benefits with positive attitudes and behaviors in return. Drawing upon this theory, researchers found that ethical leadership has a positive relationship with work engagement [12].

Greenhaus and Powell (2006) suggested that WFE represents a transfer of positive experiences from the work role to the family role [5]. In other words, positive affect created in the workplace can promote functioning in family through the process of spillover. For example, employees who gain positive affect from the workplace may display positive affect to their family members (e.g., spouse and children) at home, and thus enhance their family function. Role engagement has been suggested to increase individual's positive emotions. Researchers found that work engagement is not only important for one's own performance, but also for one's partner's performance [13]. A more recent research has identified that work engagement is an important predictor of WFE [14].

As discussed above, ethical behaviors of the leaders may enhance employees' work engagement due to the social exchange motivation, which in turn promote their family life quality. Therefore, it is reasonable to argue that work engagement can be an important mediating mechanism in the relationship between ethical leadership and WFE. Thus, this study proposes the following hypothesis:

H3: Work engagement will mediate the positive relation between ethical leadership and WFE.

\section{Methods}

\section{Participants.}

The participants in this study were full-time employees in China. In all, 186 (62\%) participants completed all sections of the survey. Out of these participants, $35.5 \%$ are female, with the majority $(62.4 \%)$ being married. Approximately $97.8 \%$ were 40 years old or less.

\section{Measurement.}

All the measurements were rated on a 5-point scale that ranged from 1 (strongly disagree) to $5=$ (strongly agree).

Ethical Leadership was measured using the 10-item scale developed by Brown et al. [2]. In the present study, Cronbach's $\alpha$ for ethical leadership was 0.95 .

Work-to-family enrichment (WFE) was measured using the 3-item scale developed by Grzywacz and Bass [15]. In the present study, Cronbach's $\alpha$ for WFE was .76.

Job autonomy was measured using the 3-item scale developed by Spreitzer [16]. In the present study, Cronbach's $\alpha$ was .85.

Work engagement was measured by using four items which were taken from Schaufeli, Bakker, and Salanova's questionnaire [17]. Cronbach's alpha for this scale was .81. 
According to previous research, this study statistically controlled for position ( 1 = non-supervisory, $2=$ first-level supervisor, $3=$ middle-level manager, $4=$ top-level manager $)$ gender $(1=$ male, $2=$ female), age ( $1=30$ or less, $2=31-35,3=36-40,4=41$ or more), and marriage status ( $1=$ single, $2=$ married) in all analyses to rule out alternative explanations for our findings.

\section{Results}

\section{Descriptive Statistics and Correlational Analyses.}

Table 1 shows the means, standard deviations, and inter-correlations of all study variables. The patterns of correlations are consistent with both theory and previous research. Ethical leadership was positively related to job autonomy, work engagement and WFE. Furthermore, WFE was positively related to both job autonomy and work engagement

Table 1. Descriptive statistics and correlational analyses

\begin{tabular}{|l|c|c|r|r|r|r|r|c|}
\hline & 1 & 2 & 3 & 4 & 5 & 6 & 7 & 8 \\
\hline 1. Position & 1.00 & & & & & & & \\
\hline 2. Gender & .03 & 1.00 & & & & & & \\
\hline 3. Age & .12 & $-.16^{*}$ & 1.00 & & & & & \\
\hline 4. Marital Status & .09 & .03 & .14 & 1.00 & & & & \\
\hline 5. Ethical leadership & .05 & .14 & .04 & .02 & 1.00 & & & \\
\hline 6. Autonomy & $.22^{* *}$ & -.14 & -.05 & -.05 & $.37^{* *}$ & 1.00 & & \\
\hline 7. Engagement & $.19^{*}$ & .05 & .08 & .03 & $.39^{* *}$ & .12 & 1.00 & \\
\hline 8. WFE & .13 & -.04 & $.15^{*}$ & .02 & $.36^{* *}$ & $.27^{* *}$ & $.39^{* *}$ & 1.00 \\
\hline Mean & .98 & .69 & 1.83 & 1.65 & 3.36 & 3.25 & 3.50 & 3.20 \\
\hline SD & .83 & .59 & .80 & .52 & .65 & .88 & .58 & .74 \\
\hline
\end{tabular}

\section{Hypothesis Testing.}

This study used hierarchical multiple regressions to test Hypotheses 1 - 3. In all analyses, we entered the control variables of position, gender, age and marital status first into the regression model, and then the primary study variables. Table 2 shows the regression results.

Table 2. Results of the hierarchical regression analysis

\begin{tabular}{|c|c|c|c|c|c|c|c|}
\hline & \multicolumn{2}{|c|}{ Autonomy } & \multicolumn{2}{c|}{ Engagement } & \multicolumn{3}{c|}{ WFE } \\
\hline & M1 & M2 & M3 & M4 & M5 & M6 & M7 \\
\hline Position & $.24^{*}$ & $.22^{*}$ & $.18^{*}$ & $.16^{*}$ & .11 & .10 & .01 \\
\hline Gender & $-.16^{*}$ & $-.22^{*}$ & .05 & .00 & -.02 & -.07 & -.04 \\
\hline Age & -.09 & -.12 & .06 & .04 & .14 & .11 & .12 \\
\hline Marital Status & -.05 & -.05 & .00 & .00 & .00 & .00 & .00 \\
\hline Ethical Leadership & & $.40^{* *}$ & & $.38^{* *}$ & & $.36^{* *}$ & $.19^{*}$ \\
\hline Job Autonomy & & & & $.21^{*}$ & & & $.16^{*}$ \\
\hline Work Engagement & & & & & & & $.29^{* *}$ \\
\hline$\Delta \mathrm{R}^{2}$ & $.08^{* *}$ & $.15^{* *}$ & .04 & .14 & .04 & $.13^{* *}$ & $.08^{* *}$ \\
\hline $\mathrm{F}$ & $4.01^{* *}$ & $11.09^{* *}$ & 1.89 & $7.76^{* *}$ & 1.66 & $6.95^{* *}$ & $9.25^{* *}$ \\
\hline
\end{tabular}

$* \mathrm{p}<.05 ; * * \mathrm{p}<.01$. All coefficients reported are standardized betas. 
Baron and Kenny (1986) proposed a four-step approach to establish the conditions for mediation. As can be seen in Table 2, after controlling for several demographic variables, ethical leadership was also significantly related to WFE (Model 6). Thus, Condition (a) for the mediation effect was met (H1). Ethical leadership was significantly related to job autonomy and work engagement (M2), satisfying Condition (b). WFE was positively related to job autonomy and work engagement (Model 7). Thus, Condition (c) was met. Further, after work engagement was taken into account, the effect of ethical leadership on WFE became weaker, albeit still significant (Model 7), which suggests partial mediation. To provide a more rigorous test of the mediation effect, we used the bootstrap procedure developed by Preacher and Hayes (2008) to test the indirect effect with 5,000 bootstrap samples [18]. Results showed that both the $95 \%$ confidence intervals for the indirect effects estimate of job autonomy $([.01, .15])$ and work engagement $([.05, .22])$ did not contain zero, indicating that the indirect effects were significant ( $\mathrm{H} 2$ and $\mathrm{H} 3)$. Taken together, Hypotheses 1-3 were supported, that is, job autonomy and work engagement partially mediated the relationship between ethical leadership and WFE.

\section{Discussion}

Integrating ethical leadership and work-family enrichment literature, this study explored the relationship between ethical leadership and WFE. The results showed that ethical leadership has a positive effect on employees' job autonomy and work engagement and a positive indirect effect on the experience of WFE through job autonomy and work engagement. In other words, when employees believe that they are working with an ethical leader, they are more likely to feel a sense of job autonomy and be more engaged in their jobs, which in turn, enhance their experience of WFE. These findings of this study make several important contributions to the literature.

First, this study contributes to the theoretical research on ethical leadership by exploring the effects of ethical leadership on employee work-family experience. According to scholars, supervisors have a crucial influence of the experiences of their subordinates [4]. However, existing research has largely ignored the link between leadership and employee work-family outcomes [3]. This study extended filled this gap by directly assessing the effects of ethical leadership on WFE.

Second, social learning theory and social exchange theory have been identified as two crucial mechanisms by which ethical leaders influence subordinates [2]. This study echoed the call of Li et al. (2017) to adapting other theoretical perspectives that may shed light on the role of leader behavior in relation to employee work-family outcomes by applying work-family enrichment theory to realize how ethical leadership in the workplace influenced employees' perception of WFE. Work-family enrichment theory asserts that psychological resources can be transferred from the work domain to the family domain [5]. Drawing on this theory, the current study found that job autonomy and work engagement mediate the relationship between perceived ethical leadership and WFE. In addition, the results from the current study may encourage future researchers to address the impact of leadership on work-family consequences by focusing on the mediating roles of other resources, such as skills and perspectives.

In addition to the theoretical contributions mentioned above, this research yields several practical implications. As WFE are of strategic importance to both employees and organizations [4], the findings of this study suggests that ethical leadership should draw more attention as a facilitator to organizational success and individual personal well-being. Thus, organizations should devote more effort to cultivating ethical leadership behavior among managers at different levels. Meanwhile, ethics should also be emphasized during recruitment and promotion processes.

\section{Acknowledgements}

This research was financially supported by the Humanity and Social Science Youth foundation of Ministry of Education of China (12YJC630156), and the Fundamental Research Funds for the Central Universities (D2155990), SCUT. 


\section{References}

[1] M. Painter-Morland, Systemic leadership and the emergence of ethical responsiveness, Journal of Business Ethics, 82 (2008) 509-524.

[2] M.E. Brown, L.K. Treviño, D.A. Harrison, Ethical leadership: A social learning perspective for construct development and testing, Organizational Behavior and Human Decision Processes, 97 (2005) 117-134.

[3] A. Li, K.D. McCauley, J.A. Shaffer, The influence of leadership behavior on employee work-family outcomes: A review and research agenda, Human Resource Management Review 27 (2017) 458-472.

[4] L.A. McNall, J.M. Nicklin, A.D. Masuda, A meta-analytic review of the consequences associated with work-family enrichment, Journal of Business and Psychology, 25(2010) 381-396.

[5] J.H. Greenhaus, G.N. Powell, When work and family are allies: A theory of work-family enrichment, Academy of Management Review, 31 (2006) 72-92.

[6] Y. Liao, X. Liu, H.K. Kwan, J. Li, Work-family effects of ethical leadership, Journal of Business Ethics, 128 (2015) 535-545.

[7] L.T. Eby, W.J. Casper, A. Lockwood, C. Bordeaux, A. Brinley, Work and family research in IO/OB: Content analysis and review of the literature (1980-2002), Journal of Vocational Behavior, 66 (2005) 127-197.

[8] M.E. Brown, L.K. Treviño, Ethical leadership: A review and future directions, Leadership Quarterly, 17 (2006) 595-616.

[9] O.L. Siu, J.F. Lu, P. Brough, C.Q. Lu, A.B. Bakker, T. Kalliath, K. Shi, Role resources and work- family enrichment: The role of work engagement, Journal of Vocational Behavior, 77 (2010) 470-480.

[10]H. Zhang, H.K. wan, A.M. Everett, Z. Jian, Servant leadership, organizational identification, and work-to-family enrichment: The moderating role of work climate for sharing family concerns, Human Resource Management, 51 (2012) 747-768.

[11]R.F. Piccolo, R. Greenbaum, D.N. Den Hartog, R. Folger, The relationship between ethical leadership and core job characteristics, Journal of Organizational Behavior, 31 (2010) 259-278.

[12]A.S. Engelbrecht, G. Heine, B. Mahembe, Integrity, ethical leadership, trust and work engagement, Leadership \& Organization Development Journal, 38 (2017) 368-379.

[13] A.B. Bakker, E. Demerouti, The crossover of work engagement between working couples: A closer look at the role of empathy, Journal of Managerial Psychology, 24 (2009) 220-236.

[15] J.G. Grzywacz, B.L. Bass, Work, family, and mental health: testing different models of work-family fit, Journal of Marriage and the Family, 65 (2003) 248-262.

[16] G.M. Spreitzer, Psychological empowerment in the workplace: Dimensions, measurement, and validation, Academy of Management Journal, 38 (1995) 1442-1465.

[17] W.B. Schaufeli, A.B. Bakker, M. Salanova, The measurement of work engagement with a short questionnaire: A cross-national study, Educational and Psychological Measurement, 66 (2006) 701-716.

[18]K.J. Preacher, A.F. Heyes, Asymptotic and resampling strategies for assessing and comparing indirect effects in multiple mediator models. Behavior Research Methods, 40 (2008) 879-891. 